\title{
Combination of three-dimensional reconstruction technique and blood parameters for the evaluation of tumour burden and prognosis in patients with hepatocellular carcinoma undergoing liver resection
}

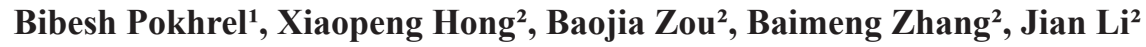

\section{Abstract}

Introduction: Hepatic resection is the mainstay of treatment for Hepatocellular carcinoma (HCC). Three-dimensional technique helps to create an image of the liver using pre-operative computed tomography (CT) scans which can be used for planning of surgery and counselling of the patient. Various lab parameters have also been shown to affect the prognosis of HCC. This study was designed to analyse whether three dimensional technique and blood parameters are correlated with the prognosis among HCC patients following hepatic resection and also to find a relation between these variables.

Methods: Data were collected retrospectively to recruit HCC patients treated between January 2010 and December 2016. Seventy-three HCC patients without extrahepatic metastasis, who underwent hepatic resection and had pre-operative CT scan done in our centre were enrolled for this study. IQQA ${ }^{\circledR}$ was used to create a three-dimensional imaging, and various related laboratory parameters were also collected. Outcomes of these patients were calculated to establish a relationship between IQQA, laboratory results and the prognosis of the patients.

Results: The one, three and five year overall survival (OS) rates were 94.4\%, 53.3\% and 19.4\% respectively, and disease-free survival (DFS) rates were $75 \%, 31.3 \%$ and $12.8 \%$ respectively. IQQA percentage of tumor was statistically significant for both OS and DFS. In the multivariate analysis, patients having lymph node metastasis, vascular invasion and high pre-op CA 19-9 had lower DFS rate, while it increased in those with high pre-op albumin. Other significant variables for OS were lymph node metastasis, Child Pugh score, high pre-op alpha fetoprotein (AFP) value and high CA 19-9. Resected segments, lymph node metastasis, liver cirrhosis, blood loss and hospital stay were significant between the two IQQA subgroups (IQQA $\leq 30 \%$ and IQQA $>30 \%$ ). Additionally in these IQQA subgroups, significant difference was found between DFS and OS.

Conclusion: IQQA software is helpful to create a 3D image of the liver, and can be combined with lab parameters to predict prognosis for patients with liver cancer. Therefore, this three-dimensional imaging technique can be used as a routine technique for patients undergoing liver resection.

Keywords: 3D reconstruction technique; HCC; Hepatic resection; IQQA.

\section{Author affiliations:}

${ }^{1}$ Department of Neurosurgery, Kathmandu Medical College Teaching Hospital, Kathmandu, Nepal.

${ }^{2}$ Department of Hepatobiliary Surgery, the Fifth Affiliated Hospital of Sun Yat-sen University, Zhuhai 519000, China.

\section{Correspondence:}

Dr. Bibesh Pokhrel, Registrar, Department of Neurosurgery, Kathmandu Medical College Teaching Hospital, Sinamangal, Kathmandu, Nepal

Email: bibeshpokharel@yahoo.com

ORCID: https://orcid.org/0000-0002-19979859

Disclosures:

Ethical Clearance: IRB of 5th Affiliated Hospital, China

Conflict of interest: None

Financial aid: None

Copyright information:

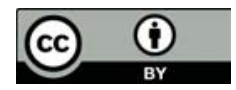

Authors retain copyright and grant the journal right of first publication with the work simultaneously licensed under Creative Commons Attribution License under CC-BY 4.0 that allows others to share the work with an acknowledgement of the works's authorship and initial publication of this journal.

How to cite this article:

Pokhrel B, Hong X, Zou B, Zhang B, $\mathrm{Li}$ J. Combination of three-dimensional reconstruction technique and blood parameters for the evaluation of tumour burden and prognosis in patients with hepatocellular carcinoma undergoing liver resection. J Soc Surg Nep. 2020 Dec;23(2):18-30.

DOI:

https://doi.org/10.3126/jssn.v23i2.35799 


\section{Introduction}

Hepatocellular carcinoma (HCC) accounted for around 746,000 deaths worldwide in 2012, which was the second most common cancer related deaths of all cancers. Worldwide, it is the fifth and ninth most common cancer in male and female respectively. ${ }^{1}$ Some underlying liver disease is the cause for most of the cases of HCC. As there is growing incidence of this disease, many researches has been done for HCC and several clinical practice guidelines have been proposed by several researchers for its treatment and management. The prognosis of patients with $\mathrm{HCC}$ after hepatic resection (HR) may be done by preoperative multi-phase contrast-enhanced CT parameters. ${ }^{2}$ Similarly, prior to the hepatic resection, functional residual liver volume and the future remnant liver (FRL) volume must be evaluated. These pre-operative evaluations along with other systemic and hepatic function test will provide a great deal of information about the surgery which can reduce rate of post-operative complications. ${ }^{3}$ Different studies have set a maximum resection window for hepatic resection. A limit of 20 to $30 \%$ of total volume of the liver as FRL after hepatic resection is mandatory for patients having normal liver in order to avoid post-operative complications. Patients having injured liver should have a FRL volume of $30-40 \%{ }^{4}$ Tang et al. suggested a threshold of $40 \%$ and $50 \%$ FRL for safe liver resection. ${ }^{5}$ There are various three- dimensional reconstruction software available for the surgeons to increase intraoperative vision by providing detailed anatomical and pathological structures which could be encountered intraoperatively. The IQQA ${ }^{\circledR}$-Liver provides a fast real time assessment of the liver, hepatic lobes and segments, vascular structures of the liver and hepatic lesions by using a Multiple Detector Computed Tomography (MDCT) scan.

This study investigated the relationship between IQQA and blood parameters with the prognosis among HCC patients. It also analysed whether resected liver volume and preoperative CT scan had correlation with the overall survival and disease free survival.

\section{Methods}

\section{Patients:}

This study was approved by the ethical committee of the 5th Affiliated Hospital of Sun-Yat Sen University, Zhuhai, China. The diagnosis was made by evaluating the radiographical images (CT/ Magnetic Resonance Imaging (MRI) or both), abdominal ultrasonography and serum concentration of $\alpha$-fetoprotein (AFP) $\geq 400 \mathrm{ng} / \mathrm{ml}$.

The selection criteria were as follows:

i) patients who underwent HR with negative surgical margin confirmed by histological examination, either laparoscopically or open technique

ii) patient who completed a follow up of at least one year after the surgery

iii) patients who had pre-operative CT scan done in our hospital, and

iv) patients whose first diagnosis was HCC without extrahepatic metastasis.

Exclusion criteria were:

i) patients who underwent liver surgery for any other liver disease or for HCC before

ii) patients who were treated with locoregional approaches like radiofrequency ablation(RFA) and TACE before HR for $\mathrm{HCC}$, and

iii) Unable to complete the HR because of more extensive disease than predicted from pre-op CT scans.

All the operations were performed in the same department by the same team of surgeons. Out of 249 patients, 65 patients were excluded as those patients had no preoperative CT scan or only had MRI. Twenty-one patients were not operated because of advanced disease. The remaining 132 patients underwent various kinds of HR according to the location of the tumor. Furthermore, 43 patients were also not included in this study because the patients underwent surgery more than once or patients had metastasis to other organs. Lastly, 16 more patients were excluded due to failure to follow up or other inclusion criteria not being met. Finally, a total of 73 patients were included in this study. A flowchart has been provided to make the patient selection process more clear (Figure 1).

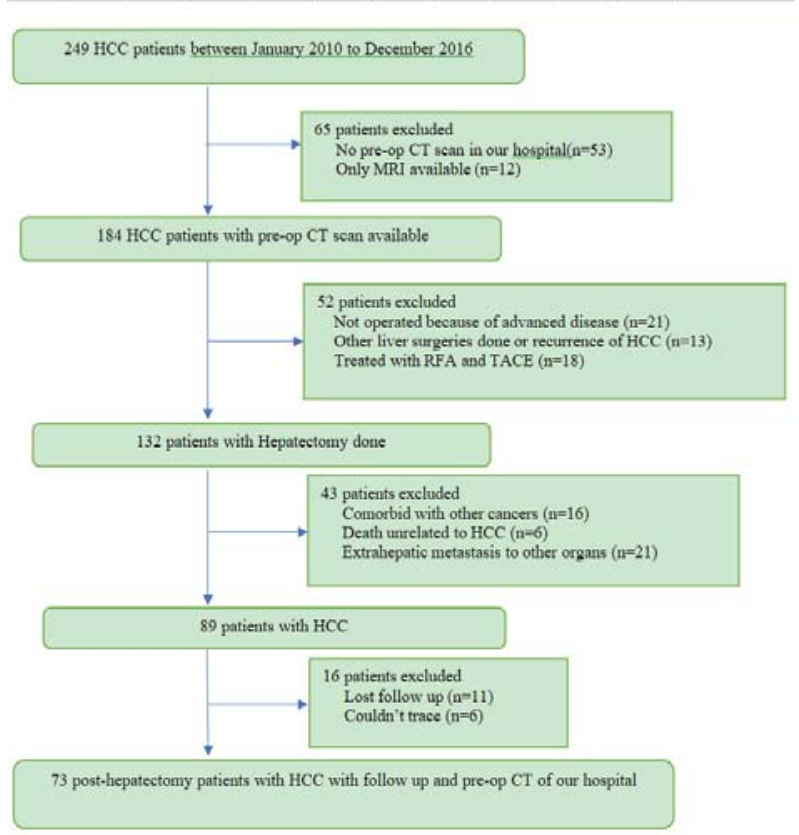

Figure 1. Flowchart for patient inclusion and exclusion

\section{Clinicopathological variables:}

All data and pre-operative CT scan images used in this study were extracted from the electronic record section and all the database of the department of radiology CT imaging centre respectively. Patients' clinical, lab findings, radiological, operative, pathological, follow up and survival data were analyzed retrospectively. Pre-operative, 1 st day 
post-operative, 4-6 weeks post-operative and 1-3 years post-operative values for various laboratory parameters namely white blood cell (WBC) count, Neutrophil (N) count, lymphocyte (L) count, platelet (PLT) count, alanine aminotransferase (ALT), aspartate aminotransferase (AST), total bilirubin (TBil), direct bilirubin (DBil), gammaglutamyl transpeptidase (GGT), total protein (TP), albumin, prothrombin time and international normalized ratio (INR), hepatitis B/C, AFP, serum urea (urea), serum creatinine $(\mathrm{Cr})$ were noted. Apart from these lab parameters, patient characteristics such as age, sex, blood group, presence of other diseases, hospital stay, duration of operation, and size of tumor resected were also collected and analyzed. Threedimensional reconstruction software IQQA ${ }^{\circledR}$-Liver (EDDA Technology, Inc. NJ, USA) was used to evaluate the preop CT scan to determine the volume of primary tumor. IQQA $^{\circledR}$-Liver was used to make a 3D comprehensive, real time image of individual patient's liver anatomy. CT scan was done after injecting a contrast medium in three phases (arterial phase, portal venous phase, and delayed phase) or four phase contrasts enhanced (pre-contrast, arterial phase, portal venous phase, and delayed phase.). The radiological diagnosis and tumor margin for HCC in CT scan were done by consulting a radiologist and using CT scan report for each individual patient before making a three-dimensional image by IQQA ${ }^{\circledR}$-Liver software. Presence or absence of lymph node metastasis was discovered from the operative findings record. Vascular invasion (macrovascular or microvascular) was said to be present if it was obvious in pre-operative cross sectional imaging or found to be positive in microscopic lab report respectively. The preoperative APRI (aspartate aminotransferase to platelet count ratio index) and pre-operative NLR (NeutrophilLymphocyte ratio) were determined.

NLR = Neutrophil count / Lymphocyte count $\mathrm{APRI}=[\{\mathrm{AST}(\mathrm{IU} / \mathrm{L}) /$ upper limit $\operatorname{normal}(40)\} /$ PLT(x109/L)] x 100

\section{CT imaging protocol:}

All the CT scans were performed within two weeks prior to resection with a 16 -section (Siemens) or a 64 section (Somatom definition flash, Siemens, Germany) depending on the year CT scanning was done. The scans were done from the upper level of the diaphragm to the lower abdomen craniocaudally. Iopamidol (300mg of iodine/ml, Iopamidol, Schering, Germany), a non-ionic contrast media, at $1.5 \mathrm{ml} /$ $\mathrm{Kg}$ was injected through an 18 or 20 -gauge venous cannula placed in a peripheral vein using a pressure syringe pump at the rate of $2.5 \mathrm{ml} / \mathrm{s}$ followed by a saline flush. The scan parameters used were as follows: effective current, $195 \mathrm{Ma}$; detector configuration, $64 * 0.6 \mathrm{~mm}$; rotation time, $0.5 \mathrm{~s}$; field of view, $300-450 \mathrm{~mm}$; reconstruction interval, $1 \mathrm{~mm}$; tube potential, $100 \mathrm{kVp}$; matrix size, $512 * 512$. A slice thickness of $2 \mathrm{~mm}$ was used to reconstruct the Coronal and sagittal images. To evaluate the liver morphology and vascular anatomy, the scans were obtained at fixed delays (arterial phase 30 seconds, venous phase 50 seconds and delay 180 seconds) after the injection of the contrast agent.

\section{Using IQQA ${ }^{\circledR}$-Liver:}

EDDA technology introduced IQQA ${ }^{\circledR}$-Liver Suite at the $96^{\text {th }}$ Scientific Assembly and Annual Meeting of the Radiological Society of North America (RSNA). It combines modern imaging techniques to help the surgeons in diagnosis, treatment planning, intra-operative guidance and post-operative assessment of the patient.

Multiphasic images of CT scan were used to create 3D segmentation of the liver as well as the tumor. The tumor lesion had to be marked in any of the three/four phases of the CT scan. The contours of the tumor were then outlined in intermediate slices without missing the first and the last slice. The boundaries of liver were marked automatically by the software, but manual correction had to be done on some axial image of the liver boundaries. Large vessels, gall bladder fossa, inferior venacava, and fissures were excluded from the boundary of the liver to give an actual size of the liver. Then the software constructed the 3D image of the liver and the tumor. Hepatic vein, portal vein, and hepatic artery were also marked separately to create an individual 3D image of each blood vessel. The liver was then separated into eight Couinaud segments semi automatically by the software. Consequently, a single 3D image was obtained by combining all these factors to give a detailed overview of the tumor location with respect to the liver segments and the vascularity. Finally, a diagnostic report was prepared which calculated the liver volume,

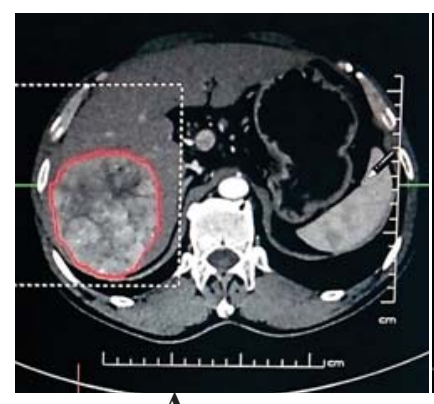

A

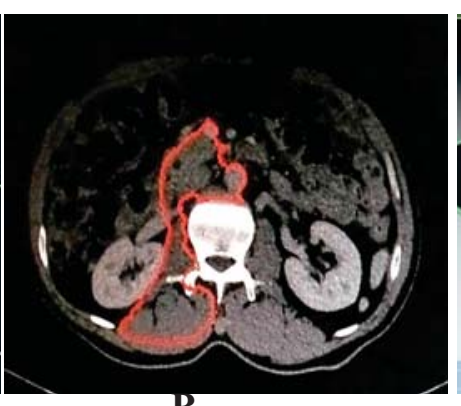

B

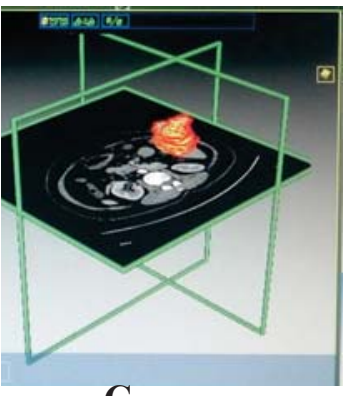

C

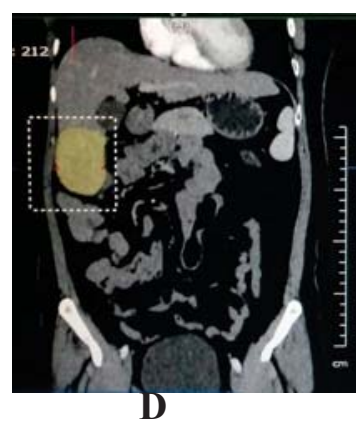

Figure 2. Transverse contrast enhanced CT images of the abdomen.

A: Arterial phase CT image showing HCC (circled in red) in reference to the liver boundary in IQQA-CT software at section VI of liver.

B: Delayed phase CT image. The portion outlined in red is automatically done by IQQA-CT software to be the liver which had to be manually removed.

software

plane of the abdomen in relation to the tumor as outined by IAAQ-CT D: Coronal plane of the abdomen showing HCC in comparison to other structures (in yellow). 
lesion volume in conjunction with a detailed report of the 3D constructed image (Figure 2).

\section{Surgical Procedure:}

Patients were selected for this study if they had undergone surgery for HCC. All the surgeries were done by the same team of surgeons. Surgery was based on the location, size and number of tumors, remaining post-operative liver volume and the general status of the patient. The open versus laparoscopic resection was decided by the surgeon's preference, the location of the tumor and previous history of surgery. Surgical procedure was based on Couinaud classification of liver segments which included minor hepatectomy (1-2 segments), major hepatectomy ( $\geq 3$ segments) or wedge resection. Whether to perform cholecystectomy and splenectomy was decided according to the location of the tumor and prior history of other underlying pathologies respectively.

\section{Patient follow up:}

Initial patient follow up were done according to the protocol of our hospital for HCC. Patients were advised to follow up for three consecutive months post operatively, and then re-examined every 3-6 months subsequently. The duration of the follow up was calculated from the date of operation to the last day of study or the death of the patient. The last day of the follow up to this study was 29th December 2017. During the first follow-up at one month, the level of serum $\alpha$-fetoprotein and liver function test were measured and similarly, given that patients did not have any complications, they underwent enhanced CT scan of the chest and abdomen at three month followup time point. If any significant findings were detected, further investigations were done to confirm the recurrence or metastasis of the tumor. The follow up patient data were collected from the inpatient and outpatient records, as well as the records of CT scan. Some patients who did not show up for follow up were contacted and enquired through phone calls. The duration from the day of liver resection to the time of $\mathrm{HCC}$ related death or the last follow-up point for our study was defined as the Overall survival (OS).On the other hand, the Disease free survival (DFS) was measured as the duration between resection of the liver to the point when radiological evidences of tumor recurrence or metastasis were detected.

\section{Recurrence treatment:}

The same evaluation criteria, which was used for the first resection, was used to evaluate the patients with intrahepatic recurrence. These patients underwent either secondary hepatectomy or other locoregional approaches like RFA and TACE or given sorafenib therapy depending on the overall condition of the patient. Patients with extrahepatic recurrence or distant metastasis were judged according to the sites involved and further decisions were taken. Patients with a likelihood of getting a liver transplant were advised for further consultation in other centers.

\section{Statistical analysis:}

All the statistical analyses were performed using IBM SPSS statistics version 20 (IBM, NY, USA), and all the data were transferred to SPSS from Microsoft Excel (Microsoft Office 2016). The categorical data were calculated as the number and percentage of observations. The Cox proportional hazard models were used for univariate and multivariate analysis to predict the relationship between DFS and OS with the other study variables. Statistically significant study variables in the univariate analysis were used for the multivariate Cox proportional analysis.

Kaplan-Meier method was used to generate hazard ratio and $95 \%$ confidence interval to find a cut-off value between IQQA \% and DFS and OS. The patients were categorised into two groups based on this probability values for DFS and OS. Survival curves for DFS and OS were also estimated using Kaplan-Meier method in significant $(\mathrm{p}<0.05)$ study variables in multivariate analysis. Characteristics of different study variables were divided into two groups and expressed as mean (range). Group differences between categorical data were analyzed using either $\chi^{2}$ test or Fisher exact test (2-tailed) where appropriate. Continuous data between groups was analyzed by student's t-test (sig. 2 tailed) for Equality of means with equal variances not assumed.

Survival curves were estimated using GraphPad Prism version 6 (GraphPad Software, Inc California) in various IQQA\% groups and the intergroup difference was evaluated using log-rank test for significance in DFS and OS. All the probability values in the calculation were 2 sided, and $\mathrm{p}<0.05$ were considered to have a statistically significant.

\section{Results}

\section{Clinical and Tumor Characteristics of HCC}

Table 1 summarizes the baseline characteristics of patients enrolled in this study. Of the total participants, 67(91.8\%) were male and $6(8.2 \%)$ were female with mean age of $52.85 \pm 11.51$ years (range $=29-76$ years, median $=53$ years). Comparatively higher proportions of the patients were in the 51-60 years age group (28.8\%), while only five (6.8\%) were older than 70 years. Similarly, 27 patients $(37 \%)$ had blood group A+ followed by $35.6 \%$ (26 patients) with $\mathrm{O}+$ blood group. $53.4 \%$ of patients (39 in number) had a history of hepatitis B for more than 10 years, although there were $83.6 \%$ of hepatitis B patient in total. At the time of diagnosis, 49.3\% (36 patients) had prior liver cirrhosis. Even though minor (1-2segments) hepatectomy was done for 61 patients (83.6\%) compared to that of major ( $\geq 3$ segments) hepatectomy done for 12 patients, laparoscopic surgery could only be performed on 16 patients $(21.9 \%)$ while the remaining 57 patients $(78.1 \%)$ had open surgery. HCC was mostly located on the right side of the liver (76.7\%) compared to that of left side (16.4\%) and both the right and the left sides $(6.9 \%)$. 
Table 1. Demographics and characteristics of all patients $(n=73)$

\begin{tabular}{|c|c|c|c|}
\hline Characterstics & & $\mathbf{N}$ & $\%$ \\
\hline \multirow[t]{2}{*}{ Sex } & Male & 67 & 91.8 \\
\hline & Female & 6 & 8.2 \\
\hline \multirow[t]{5}{*}{ Age (years) } & $\leq 40$ & 13 & 17.8 \\
\hline & $41-50$ & 18 & 24.7 \\
\hline & $51-60$ & 21 & 28.8 \\
\hline & $61-70$ & 16 & 21.9 \\
\hline & $>70$ & 5 & 6.8 \\
\hline \multirow[t]{4}{*}{ Blood group } & $\mathrm{O}+$ & 26 & 35.6 \\
\hline & $\mathrm{A}+$ & 27 & 37.0 \\
\hline & $\mathrm{B}+$ & 15 & 20.6 \\
\hline & $\mathrm{AB}+$ & 5 & 6.8 \\
\hline \multirow[t]{3}{*}{ Hepatitis B } & Positive ( $\geq 10$ years) & 39 & 53.4 \\
\hline & Positive $(<10$ years) & 22 & 30.2 \\
\hline & Negative & 12 & 16.4 \\
\hline \multirow[t]{2}{*}{ Cirrhosis } & Positive & 36 & 49.3 \\
\hline & Negative & 37 & 50.7 \\
\hline \multirow[t]{2}{*}{ Hepatectomy } & $\begin{array}{l}\text { Minor (1-2 seg- } \\
\text { ments) }\end{array}$ & 61 & 83.6 \\
\hline & Major ( $\geq 3$ segments & 12 & 16.4 \\
\hline \multirow[t]{2}{*}{ Surgery } & Open & 57 & 78.1 \\
\hline & Laparoscopic & 16 & 21.9 \\
\hline \multirow[t]{3}{*}{ Tumor location } & Right side & 56 & 76.7 \\
\hline & Left side & 12 & 16.4 \\
\hline & Both right and left & 5 & 6.9 \\
\hline
\end{tabular}

Twenty-eight patients were alive and 45 patients were deceased by the end of the study period. The average OS time was $31.16 \pm 18.71$ months (range $=3-90.7$ months). There were 38 cases of recurrence and 35 patients had no recurrence during the study phase. The average DFS time was $24.87 \pm 19.47$ months (range $=1-90$ months).

Prognostic factors associated with DFS and OS in HCC Various baseline and clinicopathological factors were investigated to find the relation with recurrence of HCC in patients after curative hepatectomy. For the univariate and multivariate analysis, parameters including patients age ( $\geq 60$ years or $<60$ years), blood group ("O" or Non "O"), and levels of total bilirubin ( $>20.4$ or $\leq 20.4 \mu \mathrm{mol} / \mathrm{L})$, Albumin $(>40$ or $\leq 40 \mathrm{~g} / \mathrm{L})$, ALT $(\geq 40$ or $<40 \mathrm{U} / \mathrm{L})$, GGT ( $\geq 45$ or $<45 \mathrm{U} / \mathrm{L})$, PT $(\geq 13$ or $<13$ seconds), NeutrophilLymphocyte ratio(NLR) $(\geq 2.7$ or $<2.7)$, APRI $(>1.68$ or $\leq 1.68)$, AFP ( $>400$ or $\leq 4000 \mathrm{ng} / \mathrm{ml})$, CA $19-9$ ( $>27$ or $\leq 27 \mathrm{U} /$ $\mathrm{ml})$ were divided into two subgroups depending upon the
Kaplan Meier analysis for DFS and OS at different CTIQQA\% (Table 4). All the reference values used in this study were pre-operative laboratory values. Presence or absence of lymph node metastasis, vascular invasion, cirrhosis and hepatitis B (positive or negative) were also divided into subgroups.

Univariate analysis showed CT-IQQA\%, lymph node metastasis, vascular invasion, liver cirrhosis, resected segment ( $<3$ or $\geq 3$ ), total bilirubin, serum albumin, NLR and CA 19-9 to be the factors associated with recurrence. Though, in multivariate analysis, only CT-IQQA\%, lymph node metastasis, vascular invasion, serum albumin and CA 19-9 showed association with the recurrence rates (Table 2).

Similarly, different prognostic factors were investigated to find the relation with cancer related survival following curative hepatectomy. Univariate analysis showed CTIQQA\%, lymph node metastasis, Child Pugh score, resected segment $(<3$ or $\geq 3$ ), total bilirubin, AFP and CA 19-9 to be significant factors associated with survival. Multivariate analysis of those factors showed only CTIQQA\%, lymph node metastasis, Child Pugh score, CA 19-9 and AFP to be statistically significant to survival (Table 3).

\section{Cut-off value for CT-IQQA\% to predict DFS and OS in $\mathrm{HCC}$}

Kaplan Meier analysis was used to find significance between DFS and OS with different levels of CT-IQQA\% to predict a common cut-off value. Kaplan Meier showed statistically significant value $(\mathrm{p}<0.05)$ for both DFS and OS, and CT-IQQA $\%$ in $20 \%, 25 \%$ and $30 \%$ of CT-IQQA \% but at 35\% CT-IQQA\%, the DFS was not significant $(p=0.4229)$ even though OS had a significant $\mathrm{p}$ value. In accordance with this finding, two groups were divided based on CT-IQQA $\%$ as CT-IQQA $>30 \%$ and CTIQQA $\leq 30 \%$.(Table 4)

Baseline comparison between two CT-IQQA\% groups The two groups divided were IQQA $\leq 30 \%$ and IQQA $>30 \%$. Group 1 (IQQA $\leq 30 \%$ ) with 60 patients with mean age of 51.7years (range $=32-73$ years) was compared with that of group 2 (IQQA $>30 \%$ ) with 13 patients with mean age of 58.15 years (range $=29-76$ ). There was statistically significant difference between two groups for different characteristic variables. Resected segment $(<3$ or $\geq 3$ ), lymph node metastasis, presence/absence of cirrhosis, intraoperative blood loss and hospital stay were statistically significant $(\mathrm{p}<0.05)$. Hospital stay in group 2 was higher on an average of 26.68 days (range $=16$ 40days) compared to group 1 with an average of 21.61 days (range $=10-35)$ (Table 5). 
Table 2. Univariate and multivariate analysis of prognostic factors associated with disease free survival(DFS) of patients in HCC. $(*=p<0.05)$

\begin{tabular}{|c|c|c|c|c|}
\hline \multirow[t]{2}{*}{ Variables } & \multicolumn{2}{|c|}{ Univariate } & \multicolumn{2}{|c|}{ Multivariate } \\
\hline & P value & HR $(95 \% C I)$ & P value & HR $(95 \%$ CI $)$ \\
\hline $\begin{array}{l}\text { Age } \\
\geq 60 \text { years vs }<60 \text { years }\end{array}$ & 0.156 & $1.635(0.828-3.227)$ & & \\
\hline $\begin{array}{l}\text { Gender } \\
\text { Male vs Female }\end{array}$ & 0.545 & $0.643(0.154-2.689)$ & & \\
\hline CT-IQQA (\%) & $0.000 *$ & $1.044(1.023-1.066)$ & $0.043^{*}$ & $1.041(1.001-1.083)$ \\
\hline $\begin{array}{l}\text { LN metastasis } \\
\text { Present vs Absent }\end{array}$ & $0.002 *$ & $0.332(0.167-0.662)$ & $0.003 *$ & $0.292(0.128-0.664)$ \\
\hline $\begin{array}{l}\text { Vascular Invasion } \\
\text { Present vs Absent }\end{array}$ & $0.016^{*}$ & $2.339(1.174-4.659)$ & $0.028^{*}$ & $2.318(1.095-4.909)$ \\
\hline $\begin{array}{l}\text { HBsAg } \\
\text { Positive vs Negative }\end{array}$ & 0.155 & $2.363(0.723-7.724)$ & & \\
\hline $\begin{array}{l}\text { Cirrhosis } \\
\text { Positive vs Negative }\end{array}$ & $0.048^{*}$ & $2.005(1.005-4.000)$ & 0.522 & $1.298(0.584-2.882)$ \\
\hline $\begin{array}{l}\text { Blood Group } \\
\text { O vs Non-O }\end{array}$ & 0.445 & $1.299(0.664-2.543)$ & & \\
\hline $\begin{array}{l}\text { Child Pugh } \\
\text { A, B, C }\end{array}$ & 0.183 & $1.427(0.845-2.408)$ & & \\
\hline $\begin{array}{l}\text { Resected Segment } \\
<3 \text { vs } \geq 3\end{array}$ & $0.049^{*}$ & $2.267(0.969-5.302)$ & 0.335 & $0.603(0.216-1.686)$ \\
\hline $\begin{array}{l}\text { T. Bilirubin(Pre-op) } \\
>20.4 \mu \mathrm{mol} / \mathrm{L} \text { vs } \leq 20.4 \mu \mathrm{mol} / \mathrm{L}\end{array}$ & $0.040^{*}$ & $2.019(1.033-3.945)$ & 0.431 & $0.701(0.290-1.695)$ \\
\hline $\begin{array}{l}\text { Albumin(Pre-op) } \\
>40 \mathrm{~g} / \mathrm{L} \text { vs } \leq 40 \mathrm{~g} / \mathrm{L}\end{array}$ & $0.012 *$ & $0.417(0.211-0.823)$ & $0.002 *$ & $0.246(0.104-0.585)$ \\
\hline $\begin{array}{l}\text { ALT(Pre-op) } \\
\geq 40 \mathrm{U} / \mathrm{L} \text { vs }<40 \mathrm{U} / \mathrm{L}\end{array}$ & 0.500 & $1.262(0.642-2.481)$ & & \\
\hline $\begin{array}{l}\text { GGT(Pre-op) } \\
\geq 45 \mathrm{U} / \mathrm{L} \text { vs }<45 \mathrm{U} / \mathrm{L}\end{array}$ & 0.152 & $2.144(0.755-6.088)$ & & \\
\hline $\begin{array}{l}\text { PT(Pre-op) } \\
\geq 13 \text { seconds vs }<13 \text { seconds }\end{array}$ & 0.401 & $1.342(0.676-2.664)$ & & \\
\hline $\begin{array}{l}\text { NLR(Pre-op) } \\
\geq 2.7 \text { vs }<2.7\end{array}$ & $0.021^{*}$ & $2.207(1.124-4.331)$ & 0.197 & $1.709(0.758-3.854)$ \\
\hline $\begin{array}{l}\text { APRI (Pre-op) } \\
>1.68 \text { vs } \leq 1.68\end{array}$ & 0.924 & $1.052(0.370-2.993)$ & & \\
\hline $\begin{array}{l}\text { AFP(Pre-op) } \\
>400 \mathrm{ng} / \mathrm{ml} \text { vs } \leq 400 \mathrm{ng} / \mathrm{ml}\end{array}$ & 0.153 & $1.654(0.830-3.298)$ & & \\
\hline $\begin{array}{l}\text { CA 19-9(Pre-op) } \\
>27 \mathrm{U} / \mathrm{ml} \mathrm{vs} \leq 27 \mathrm{U} / \mathrm{ml}\end{array}$ & $0.004^{*}$ & $2.693(1.367-5.303)$ & $0.013 *$ & $3.761(1.320-10.715)$ \\
\hline
\end{tabular}

\section{Discussion}

The gold standard treatment of HCC is hepatic resection, which is influenced by various factors. Among them, the size of the tumor is one of the main factors that helps to predict the possible outcome pre-operatively. Several investigative studies and aforementioned staging systems have suggested the size of the tumor as a defining variable for both the prognosis and survival. $\mathrm{BCLC}^{6}$ uses 2 and $3 \mathrm{~cm}$ cut-off value to define different stages, $\mathrm{HKLC}^{7}$ uses $5 \mathrm{~cm}$, CLIP $^{8}$ and Okuda $^{9}$ staging uses $\leq 50 \%$ or $>50 \%$ of tumor volume while CUPI ${ }^{10}$ and $\mathrm{JIS}^{11}$ uses the TNM staging for classification. Few academic papers have taken $5 \mathrm{~cm}$ as the cut-off value ${ }^{12,13}$ while others have taken $10 \mathrm{~cm}$ as the cutoff value. ${ }^{14,15}$ They concluded that patients having tumor 
less than that of their respective cut off value had better survival and recurrence. $\mathrm{Li}$ et $\mathrm{al}^{16}$ suggested that the HCC patients with total liver volume of $\leq 73.5 \mathrm{~cm}^{3}$ have a good prognosis after liver resection. However, this study failed to mention the fact that the liver sizes varies with patients. Hence, rather than setting a fixed value, finding the overall percentage of tumor volume would be more precise. In this study, a three-dimensional model is used for liver reconstruction using IQQA software using pre-operative
CT scan. Several studies supports the idea of using a 3D reconstruction software for the proper planning and better outcomes of the surgery. ${ }^{17,18}$ Furthermore, multivariate analysis in this study showed statistical significance between DFS and OS and CT-IQQA.

This research has male predominance in the study cohort with age range of 29-76 years at the time of presentation (Table 1). However, neither male gender nor older age

Table 3. Univariate and multivariate analysis of prognostic factors associated with overall survival(OS) of patients in HCC. $(*=\mathbf{p}<\mathbf{0 . 0 5})$

\begin{tabular}{|c|c|c|c|c|}
\hline \multirow[t]{2}{*}{ Variables } & \multicolumn{2}{|c|}{ Univariate } & \multicolumn{2}{|c|}{ Multivariate } \\
\hline & $P$ value & HR $(95 \% C I)$ & P value & HR $(95 \%$ CI) \\
\hline $\begin{array}{l}\text { Age } \\
\geq 60 \text { years vs }<60 \text { years }\end{array}$ & 0.239 & $1.573(0.740-3.346)$ & & \\
\hline $\begin{array}{l}\text { Gender } \\
\text { Male vs Female }\end{array}$ & 0.578 & $0.565(0.076-4.210)$ & & \\
\hline CT-IQQA (\%) & $0.000^{*}$ & $1.072(1.045-1.100)$ & $0.006^{*}$ & $1.061(1.017-1.106)$ \\
\hline LN metastasis & $0.005^{*}$ & $0.327(0.151-0.708)$ & $0.004^{*}$ & $0.262(0.106-0.646)$ \\
\hline Present vs Absent & & & & \\
\hline $\begin{array}{l}\text { Vascular Invasion } \\
\text { Present vs Absent }\end{array}$ & 0.784 & $1.111(0.524-2.357)$ & & \\
\hline $\mathrm{HBsAg}$ & 0.741 & $0.834(0.284-2.446)$ & & \\
\hline Positive vs Negative & & & & \\
\hline $\begin{array}{l}\text { Cirrhosis } \\
\text { Positive vs Negtive }\end{array}$ & 0.158 & $1.781(0.799-3.971)$ & & \\
\hline Blood Group & 0.698 & $0.856(0.392-1.874)$ & & \\
\hline O vs Non-O & & & & \\
\hline $\begin{array}{l}\text { Child Pugh } \\
\text { A, B, C }\end{array}$ & $0.000^{*}$ & $3.213(1.759-5.868)$ & $0.001 *$ & $6.691(2.201-20.337)$ \\
\hline Resected Segment & $0.000^{*}$ & $6.193(2.316-16.559)$ & 0.478 & $1.568(0.452-5.432)$ \\
\hline$<3$ vs $\geq 3$ & & & & \\
\hline $\begin{array}{l}\text { T. Bilirubin(Pre-op) } \\
>20.4 \mu \mathrm{mol} / \mathrm{L} \text { vs } \leq 20.4 \mu \mathrm{mol} / \mathrm{L}\end{array}$ & $0.026^{*}$ & $2.348(1.109-4.973)$ & 0.409 & $0.636(0.218-1.860)$ \\
\hline $\begin{array}{l}\text { Albumin(Pre-op) } \\
>40 \mathrm{~g} / \mathrm{L} \text { vs } \leq 40 \mathrm{~g} / \mathrm{L}\end{array}$ & 0.633 & $0.824(0.372-1.825)$ & & \\
\hline $\begin{array}{l}\text { ALT(Pre-op) } \\
\geq 40 \mathrm{U} / \mathrm{L} \text { vs }<40 \mathrm{U} / \mathrm{L}\end{array}$ & 0.908 & $1.047(0.478-2.296)$ & & \\
\hline $\begin{array}{l}\text { GGT(Pre-op) } \\
\geq 45 \mathrm{U} / \mathrm{L} \text { vs }<45 \mathrm{U} / \mathrm{L}\end{array}$ & 0.894 & $0.934(0.344-2.537)$ & & \\
\hline $\begin{array}{l}\text { PT(Pre-op) } \\
\geq 13 \text { seconds vs }<13 \text { seconds }\end{array}$ & 0.831 & $1.095(0.477-2.515)$ & & \\
\hline $\begin{array}{l}\text { NLR(Pre-op) } \\
\geq 2.7 \text { vs }<2.7\end{array}$ & 0.094 & $1.917(0.895-4.109)$ & & \\
\hline $\begin{array}{l}\text { APRI (Pre-op) } \\
\qquad 1.68 \text { vs } \leq 1.68\end{array}$ & 0.355 & $0.504(0.118-2.156)$ & & \\
\hline $\begin{array}{l}\text { AFP(Pre-op) } \\
>400 \mathrm{ng} / \mathrm{ml} \text { vs } \leq 400 \mathrm{ng} / \mathrm{ml}\end{array}$ & $0.005^{*}$ & $4.044(1.518-10.774)$ & $0.006^{*}$ & $5.459(1.609-18.520)$ \\
\hline $\begin{array}{l}\text { CA 19-9(Pre-op) } \\
>27 \mathrm{U} / \mathrm{ml} \text { vs } \leq 27 \mathrm{U} / \mathrm{ml}\end{array}$ & $0.002 *$ & $3.309(1.556-7.037)$ & $0.014^{*}$ & $2.894(1.235-6.777)$ \\
\hline
\end{tabular}


Table 4. Kaplan Meier analysis for DFS and OS at different CT-IQQA\%

\begin{tabular}{|c|c|c|c|c|}
\hline \multirow[t]{2}{*}{ CT-IQQA \% } & \multicolumn{2}{|c|}{ Disease free survival } & \multicolumn{2}{|c|}{ Overall Survival } \\
\hline & p-value & HR(95\%CI) & p-value & HR(95\%CI) \\
\hline $20 \%$ & $<0.001$ & $0.287(0.071-0.399)$ & $<0.001$ & $0.228(0.041-0.281)$ \\
\hline $25 \%$ & $<0.001$ & $0.265(0.033-0.316)$ & $<0.001$ & $0.200(0.021-0.186)$ \\
\hline $30 \%$ & 0.0013 & $0.334(0.075-0.524)$ & $<0.001$ & $0.170(0.008-0.097)$ \\
\hline $35 \%$ & 0.4229 & $0.659(0.175-2.060)$ & 0.0107 & $0.341(0.044-0.623)$ \\
\hline
\end{tabular}

Table 5. Patient characteristics between two IQQA groups

\begin{tabular}{|c|c|c|c|c|}
\hline Characterstics & $\begin{array}{l}\text { Group 1: } \\
\text { IQQA } \leq 30 \%(60)\end{array}$ & $\begin{array}{l}\text { Group 2: } \\
\text { IQQA>30\%(13) }\end{array}$ & Total (73) & p-value \\
\hline Age, years Mean(Range) & $51.7(32-73)$ & $58.15(29-76)$ & $52.85(29-76)$ & 0.152 \\
\hline $\begin{array}{l}\text { Gender, n (\%) } \\
\text { Male }\end{array}$ & $54(90)$ & $13(100)$ & $67(91.8)$ & 0.583 \\
\hline Female & $6(10)$ & 0 & $6(8.2)$ & \\
\hline $\begin{array}{l}\text { Resected Segment, } \mathrm{n}(\%) \\
<3 \\
\geq 3\end{array}$ & $\begin{array}{l}56(93.3) \\
4(6.7)\end{array}$ & $\begin{array}{l}5(38.5 .9) \\
8(61.5)\end{array}$ & $\begin{array}{l}61(83.6) \\
12(16.4)\end{array}$ & $<0.001 *$ \\
\hline $\begin{array}{l}\text { LN metastasis, n (\%) } \\
\text { Present } \\
\text { Absent }\end{array}$ & $\begin{array}{l}23(38.3) \\
37(61.7)\end{array}$ & $\begin{array}{l}9(69.2) \\
4(30.8)\end{array}$ & $\begin{array}{l}32(43.8) \\
41(56.2)\end{array}$ & $0.042 *$ \\
\hline $\begin{array}{l}\text { Child Pugh class } \\
\text { A } \\
\text { B } \\
\text { C }\end{array}$ & $\begin{array}{l}54(90) \\
4(6.7) \\
2(3.3)\end{array}$ & $\begin{array}{l}0 \\
9(69.2) \\
4(30.8)\end{array}$ & $\begin{array}{l}54(74) \\
13(17.8) \\
6(8.2)\end{array}$ & \\
\hline $\begin{array}{l}\text { Vascular Invasion, n (\%) } \\
\text { Present } \\
\text { Absent }\end{array}$ & $\begin{array}{l}28(46.7) \\
32(53.3)\end{array}$ & $\begin{array}{l}8(61.5) \\
5(38.5)\end{array}$ & $\begin{array}{l}36(49.3) \\
37(50.7)\end{array}$ & 0.331 \\
\hline $\begin{array}{l}\text { HBsAg, n (\%) } \\
\text { Present } \\
\text { Absent }\end{array}$ & $\begin{array}{l}50(83.3) \\
10(16.7)\end{array}$ & $\begin{array}{l}11(84.6) \\
2(15.4)\end{array}$ & $\begin{array}{l}61(83.6) \\
12(16.4)\end{array}$ & 1.000 \\
\hline $\begin{array}{l}\text { Cirrhosis, n }(\%) \\
\text { Present } \\
\text { Absent }\end{array}$ & $\begin{array}{l}27(45) \\
33(55)\end{array}$ & $\begin{array}{l}12(69.2) \\
4(30.8)\end{array}$ & $\begin{array}{l}36(49.3) \\
37(50.7)\end{array}$ & $0.048 *$ \\
\hline Blood loss, ml Mean(Range) & $612.5(50-2000)$ & $1261.54(600-3000)$ & $728.08(50-3000)$ & $0.005^{*}$ \\
\hline $\begin{array}{l}\text { Hospital stay,days } \\
\text { Mean(Range) }\end{array}$ & $21.61(10-35)$ & $26.68(16-40)$ & $22.67(10-40)$ & $0.049 *$ \\
\hline $\begin{array}{l}\text { DFS rate }(\%) \\
1 \text {-year }\end{array}$ & 83.3 & 33.3 & 75 & 0.001 \\
\hline 3-year & 35.1 & 18.1 & 31.3 & 0.463 \\
\hline 5-year & 13.8 & 10 & 12.8 & 1.000 \\
\hline $\begin{array}{l}\text { OS rate }(\%) \\
1-\text { year }\end{array}$ & 100 & 69.2 & 94.4 & 0.001 \\
\hline 3-year & 66.7 & 16.6 & 53.3 & 0.006 \\
\hline 5-year & 25 & 9.1 & 19.4 & 0.383 \\
\hline
\end{tabular}


affected DFS and OS in this study, which is in accordance to other relevant scholarly analyses. ${ }^{19}$ Also, between the two IQQA groups, no association in age and gender was observed (Table 5).

Child Pugh classification is an important prognostic factor for patients with $\mathrm{HCC}{ }^{8,11}$ In this study, most of the HCC patients have Child Pugh class A, who underwent curative HR. Previous studies have indicated that CTP class A or $\mathrm{B}$ are considered safe for elective surgery with favourable outcomes compared to CTP class C and emergency surgery which have a high mortality rate. ${ }^{20}$ Some medical professionals have indicated that, if the patient does not have uncontrollable ascites, jaundice or encephalopathy, CTP class C HCC patients can be operated without any significant difference in DFS or OS compared to CTP class $\mathrm{A}$ or $\mathrm{B} .^{21}$ This finding is consistent with our results. CTP class is found to be an independent prognostic factor for overall survival, although it does not have any association with DFS in our study.

According to The Liver Cancer Study Group of Japan; large tumor size, intrahepatic metastasis, multiple tumours, poor histological grade and gross vascular invasion are suggestive of microvascular invasion, which is often difficult to find. ${ }^{22}$ Though, macrovascular invasion can be easily diagnosed using routine cross-sectional imaging. Park et al concluded microvascular invasion with or without gross microvascular invasion did not have significant difference in terms of DFS and OS. ${ }^{23}$ However, our results showed vascular invasion as an independent prognostic factor for DFS, while it had no significant relation with OS. There is a high rate of intrahepatic tumor recurrence following hepatic resection, due to the dissemination through the intrahepatic circulation and this is inversely proportional to the DFS. ${ }^{24}$

AFP level as a prognostic factor following hepatic resection has yielded conflicting results. While some previous studies found DFS and OS to be dependent on the levels of AFP after hepatic resection, ${ }^{25}$ others have reported contradicting results. ${ }^{26}$ Our study also failed to establish AFP level as a prognostic factor. Although AFP is used for both diagnosis as well as prognosis of HCC, CA 19-9 is increasingly being used to monitor the prognosis of HCC. Studies have shown that preoperative CA $19-9>27 \mathrm{U} / \mathrm{mL}$ has a poor prognosis for $\mathrm{HCC}$ after hepatic resection. ${ }^{27}$ Our results indicated that CA 19-9 >27U/mL does not have a significant correlation with both DFS and OS, it was rather significantly inverse.

Lymph node is the most common site for metastasis of HCC, which is one of the major determinants of overall survival in such patients. ${ }^{28}$ Hasegawa et $\mathrm{al}^{29}$ found that HCC patients with histologically positive lymph node had a similar outcome with advanced HCC stage, which corresponded to JIS and UICC/AJCC staging. Hepatic resection with lymphadenectomy is the treatment modality of choice in case of lymph node metastasis. The subsequent histopathological analysis of the resected LN can help to determine the staging accurately. These results are consistent with this study as well which shows lymph node metastasis is a negative prognostic factor for DFS and OS (Figure 3).

Tao et $\mathrm{al}^{30}$ reported that the prognosis of Chinese $\mathrm{HCC}$ patients was associated with $\mathrm{ABO}$ blood group. It showed that patients with non-O blood group had reduced OS compared to that of $\mathrm{O}$ blood group patients. In this paper, we compared DFS and OS between non-O and O blood groups but there was no significant difference found.

Chronic viral hepatitis is the most common predisposing factor for HCC worldwide. Around $50 \%$ of the cases of HCC in Europe and America are caused by hepatitis C, while hepatitis B is the major factor in Asia and China. ${ }^{31}$ Several studies have been performed to predict the prognosis of HCC on the basis of viral etiology and cirrhosis, and, however, they have yielded conflicting results. Some studies have shown these as an independent factors to predict the survival, ${ }^{32}$ whereas others did not find any correlation with the prognosis. ${ }^{33}$ Viral hepatitis HCC patients present with more advanced cirrhosis even though the survival was similar to non-viral hepatitis HCC patients. ${ }^{19}$ Although cirrhosis was a significant factor for DFS in the univariate analysis, the multivariate showed no correlation. Hepatitis B positive also had no influence on DFS and OS in this study. No significant difference was found between the two groups for hepatitis B infection.

Various liver enzymes are used to assess the liver status and to predict the outcome of any liver diseases. Serum ALT and AST are released into the blood when the hepatocytes are damaged which is measured to detect liver disease. In line with other research, ${ }^{34}$ this study also didn't find any association between ALT and DFS and OS. Serum total bilirubin increases when there is a liver injury and as a result, bilirubin enters the blood causing bilirubinaemia. Li et al found that preoperative serum bilirubin $\geq 20.4 \mathrm{umol} / \mathrm{L}$ has a negative influence on the postoperative outcome..$^{35}$ Although total bilirubin value of $\geq 20.4 \mathrm{umol} / \mathrm{L}$ was found to be correlated with both DFS and OS in univariate analysis, it was found to be not significant in multivariate analysis after adjusting for all variables in multivariate analysis. GGT is a liver enzyme which increases in pancreatic diseases, renal failure, and myocardial infarction apart from hepatobiliary disease and has shown its association with different cancers as well. ${ }^{36,37}$ GGT showed no association with DFS and OS in this study although previous analyses show that GGT is a better predictor of liver specific disease than ALT. ${ }^{37}$ The recurrence of $\mathrm{HCC}$ is more common in patients with liver fibrosis, which is responsible for causing hypoalbuminemia. Hypoalbuminemia is assumed to be a favourable factor for the recurrence of $\mathrm{HCC}$, which means low recurrence rate in patients with high serum albumin levels. ${ }^{38}$ Another study has shown that patient with high albumin level decreases the likelihood of distant recurrence as well. ${ }^{39}$ In this study, high albumin levels were associated with good disease free survival; however it didn't have any effect on the overall survival of patients with HCC. 
NLR is believed to be an inflammation marker and high NLR value results in weaker antitumor immunity. Alternatively, it also shows a balance between patients immunity and inflammation, and is found to be associated with OS. ${ }^{40} \mathrm{APRI}$ is found to be an indicator and biomarker for prognosis of HCC after RFA and hepatic resection, which is reported to be predictor of DFS and OS..$^{41}$ This study demonstrated that there was no correlation between
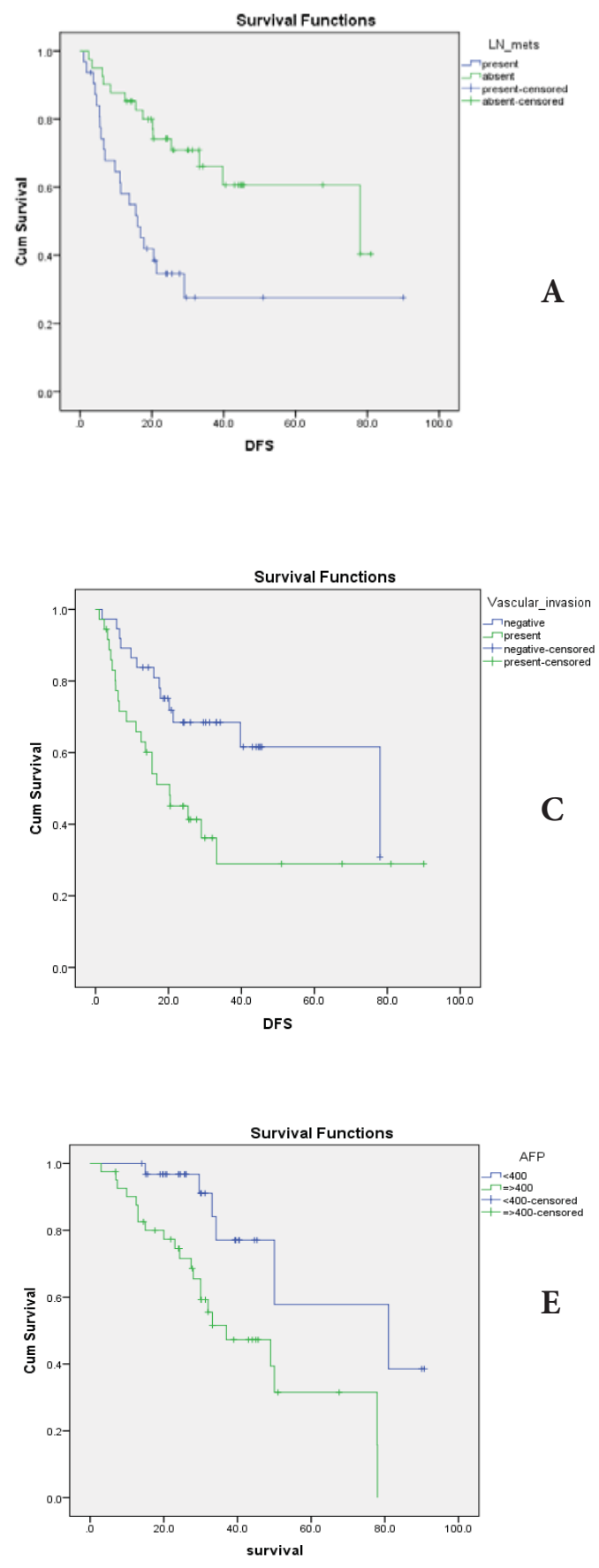

A LN metastasis DFS,

B LN metastasis OS,

C Vascular Invasion DFS,

D CA 19-9 DFS,

E AFP OS

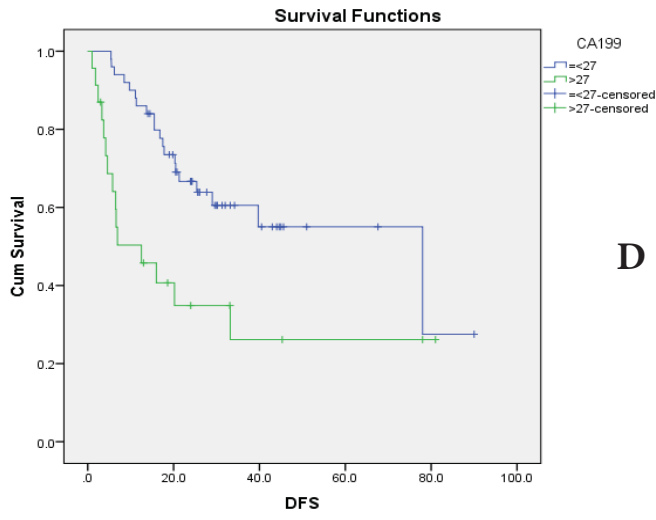

B

D

Figure 3. Kaplan-Meier survival curves stratified by various parameters 
According to the size and CT-IQQA \% of the tumor, two groups were divided as IQQA $\leq 30 \%$ and IQQA $>30 \%$. Resected segments, lymph node metastasis, presence of cirrhosis, blood loss and hospital stay were statistically significant between these two groups. It is obvious for resected segments, blood loss and hospital stay to be significant as these variables will be less in group 1 owing to less IQQA\%. Duration of the operation was not statistically related between the two groups.
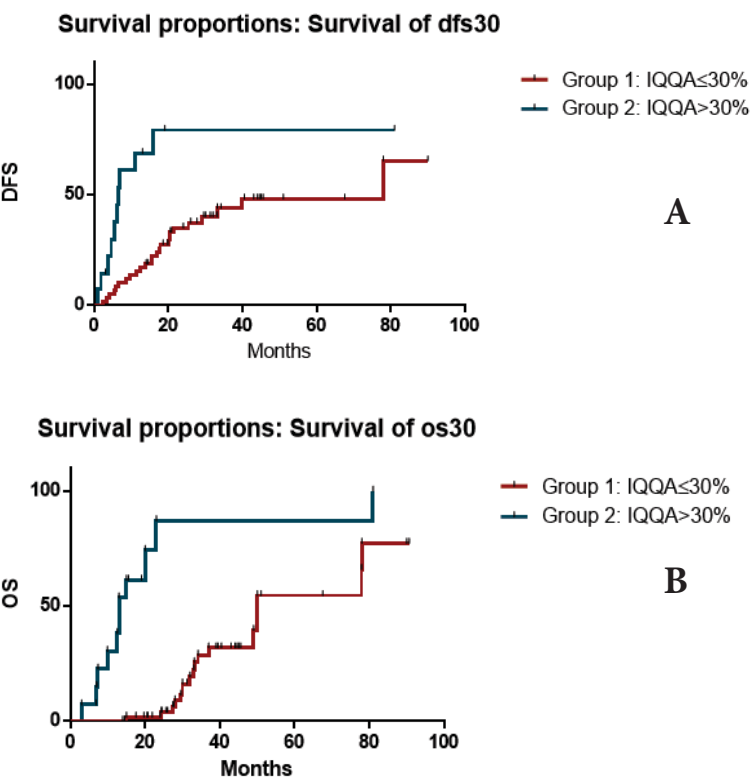

Figure 4. Graph Pad survival plots of subgroups of patients divided by IQQA-CT\%@30\% A) DFS and B) OS

The one, three and five-year overall survival rates were $94.4 \%, 53.3 \%$ and $19.4 \%$ respectively. Similarly, the one, three and five-year disease free survival rates were $75 \%, 31.3 \%$ and $12.8 \%$ respectively. One-year DFS rate between two groups was significant and one and three-year OS between the groups were also found to be statistically significant in this study (Figure 4). This finding has better OS and DFS rate than any other study ${ }^{44}$ probably because the study was done in 2012 and in a different country. The findings in this study support other studies for DFS and OS one and three-year rate. ${ }^{15,45}$ The five-year survival rate is not similar may be because of less number of patients in this study. Previous papers have shown IQQA software could be used with patients with giant $\mathrm{HCC}$ for a better prognostic outcome as well. ${ }^{46} \mathrm{FRL}>40 \%$ is said to have a satisfactory postoperative outcome after $\mathrm{HCC}$ resection. ${ }^{47}$ This study, the resected volume of liver was set at $30 \%$ which had contrasting results between different variables.

$3 \mathrm{D}$ reconstruction technique helps a surgeon to get accurate anatomic information of liver and its surrounding lesions, tissues and blood vessel. Although this is superior to a 2D imaging, the reconstruction is used using a $2 \mathrm{D}$ CT scan data. Since IQQA software provides a detailed view of the structures in 3D in every angle a surgeon wants, it can be a highly efficient method to prevent or minimize intraoperative accidents like biliary and vascular injuries. It can be useful for preoperative planning of the surgery and counselling the patients. This study combines the use of three dimensional technique with various lab parameters and general characteristics of the patient.

This is a retrospective study, and therefore, there are several limitations. All patients in the cohort are Chinese, which might have resulted in selection bias. Moreover, most of them were suffering from HBV infection and had cirrhosis. The subgroup was divided according to the percentage of IQQA, which also requires external validation and the patient in one of the subgroup was less in number compared to the other. The sample is relatively small that might not be overall representation of general population. Nevertheless, this study can be done in a larger scale to validate the findings and make $3 \mathrm{D}$ reconstruction technique a mandatory routine pre-operative test for patients undergoing hepatic resection.

\section{Conclusion}

Several variables like vascular invasion, pre-operative level of serum albumin, pre-operative CA 19-9 and alphafetoprotein determine the prognosis of HCC. Likewise, lymph node metastasis and CT-IQQA\% have shown to be an important prognostic factor for both DFS and OS in HCC patients. IQQA software helps to create a $3 \mathrm{D}$ image of the liver as well as give information about tumor volume, which could be integrated with other lab parameters. This could be used for patient counselling regarding overall survival and disease-free survival. It assists surgeon in planning the surgical techniques and options preoperatively as well as intraoperatively. Therefore, Three-dimensional technique (CT-IQQA) and lab parameters should be combined together to have a better understanding of the disease preoperatively, intraoperatively and postoperatively. We suggest CTIQQA to be used as a routine investigation prior to the hepatic resection in $\mathrm{HCC}$.

Disclosure: This paper is my Thesis for my Masters in Surgery program (2018) in Sun-Yat Sen University, Guangzhou, China.

Acknowledgements: We are indebted to the Department of Radiology, Fifth Affiliated Hospital of Sun Yat-sen University, without whose support we would not have been able to do this study. 


\section{References}

1. Chan AWH, Chan SL, Mo FKF, Wong GLH, Wong VWS, Cheung Y-S, et al. Albumin-toalkaline phosphatase ratio: a novel prognostic index for hepatocellular carcinoma. Dis Markers 2015;2015:564057.

2. Gao S-Y, Tang L, Cui Y, Li X-T, Zhang X-Y, Shan $\mathrm{J}$, et al. Tumor angiogenesis-related parameters in multi-phase enhanced CT correlated with outcomes of hepatocellular carcinoma patients after radical hepatectomy. Eur J Surg Oncol.2016 Apr;42(4):53844.

3. Lee W-C, Chen M-F. Assessment of hepatic reserve for indication of hepatic resection: how I do it. J Hepatobiliary Pancreat Surg. 2005;12(1):23-6.

4. Guglielmi A, Ruzzenente A, Conci S, Valdegamberi A, Iacono C. How Much Remnant Is Enough in Liver Resection? Dig Surg. 2012;29(1):6-17.

5. Tang J-H, Yan F-H, Zhou M-L, Xu P-J, Zhou J, Fan J. Evaluation of Computer-Assisted Quantitative Volumetric Analysis for Pre-Operative Resectability Assessment of Huge Hepatocellular Carcinoma. Asian Pac J Cancer Prev. 2013;14(5):3045-50.

6. Llovet JM, Brú C, Bruix J. Prognosis of hepatocellular carcinoma: the BCLC staging classification. Semin Liver Dis. 1999;19(3):329-38.

7. Liu P-H, Hsu C-Y, Lee Y-H, Su C-W, Hsia C-Y, Huang Y-H, et al. Hong Kong Liver Cancer Staging System Is Associated With Better Performance for Hepatocellular Carcinoma: Special Emphasis on Viral Etiology. Medicine (Baltimore). 2015;94(41):e1772.

8. A new prognostic system for hepatocellular carcinoma: a retrospective study of 435 patients: the Cancer of the Liver Italian Program (CLIP) investigators. Hepatol Baltim Md. 1998;28(3):7515 .

9. Okuda K, Obata H, Nakajima Y, Ohtsuki T, Okazaki N, Ohnishi K. Prognosis of primary hepatocellular carcinoma. Hepatol Baltim Md. 1984;4(1 Suppl):3S$6 \mathrm{~S}$.

10. Leung TWT, Tang AMY, Zee B, Lau WY, Lai PBS, Leung KL, et al. Construction of the Chinese University Prognostic Index for hepatocellular carcinoma and comparison with the TNM staging system, the Okuda staging system, and the Cancer of the Liver Italian Program staging system: a study based on 926 patients. Cancer. 2002;94(6):1760-9.

11. Kudo M, Chung H, Osaki Y. Prognostic staging system for hepatocellular carcinoma (CLIP score): its value and limitations, and a proposal for a new staging system, the Japan Integrated Staging Score (JIS score). J Gastroenterol. 2003;38(3):207-15.

12. Wang J, Xu L, Liu C, Pang H, Chen Y, Ou Q. Prognostic Factors and Outcome of 438 Chinese Patients with Hepatocellular Carcinoma Underwent Partial Hepatectomy in a Single Center. World J
Surg. 2010;34(10):2434-41.

13. Toyoda H, Kumada T, Tada T, Kaneoka Y, Maeda A. A laboratory marker, FIB-4 index, as a predictor for long-term outcomes of hepatocellular carcinoma patients after curative hepatic resection. Surgery. 2015;157(4):699-707.

14. Zhong J, Ke Y, Gong W, Xiang B, Ma L, Ye X, et al. Hepatic Resection Associated With Good Survival for Selected Patients With Intermediate and Advanced-Stage Hepatocellular Carcinoma. Ann Surg. 2014;260(2):329-40.

15. Faber W, Sharafi S, Stockmann M, Denecke T, Sinn $\mathrm{B}$, Puhl G, et al. Long-term results of liver resection for hepatocellular carcinoma in noncirrhotic liver. Surgery. 2013;153(4):510-7.

16. Li M, Zhao H, Bi X, Li Z, Huang Z, Han Y, et al. Total tumor volume predicts survival following liver resection in patients with hepatocellular carcinoma. Tumor Biol. 2016;37(7):9301-10.

17. Zhang WW, Wang HG, Shi XJ, Chen MY, Lu SC. [Significance of three-dimensional reconstruction as a method of preoperative planning of laparoscopic radiofrequency ablation]. Zhonghua Wai Ke Za Zhi. 2016;54(9):692-9.

18. Chen L, Luo HP, Dong SL, Chen XP. [Safety assessment of hepatectomy for huge hepatocellular carcinoma by three dimensional reconstruction technique]. Zhonghua Wai Ke Za Zhi. 2016;54(9):669-74.

19. Alkhalili E, Greenbaum A, Luo L, Rodriguez R, Caldwell K, Estrada OM, et al. Viral hepatitis status does not affect survival in patients with hepatocellular carcinoma. Ann Gastroenterol. 2017;30(1):101-5.

20. Befeler AS, Palmer DE, Hoffman M, Longo W, Solomon H, Di Bisceglie AM. The safety of intraabdominal surgery in patients with cirrhosis: model for end-stage liver disease score is superior to ChildTurcotte-Pugh classification in predicting outcome. Arch Surg. 2005 July;140(7):650-4; discussion 655.

21. Wu CC, Ho WL, Lin MC, Tang JS, Yeh DC, Liu TJ, et al. Is hepatic resection absolutely contraindicated for hepatocellular carcinoma in Child-Pugh class C cirrhotic patients? Hepatogastroenterology. 1999;46(26):635-9.

22. Kudo M, Kitano M, Sakurai T, Nishida N. General Rules for the Clinical and Pathological Study of Primary Liver Cancer, Nationwide Follow-Up Survey and Clinical Practice Guidelines: The Outstanding Achievements of the Liver Cancer Study Group of Japan. Dig Dis Basel Switz. 2015;33(6):765-70.

23. Park YK, Song SK, Kim B-W, Park S-K, Chung C-W, Wang H-J. Prognostic significance of microvascular invasion in tumor stage for hepatocellular carcinoma. World J Surg Oncol. 2017;15(1):225.

24. Masuda T, Beppu T, Ishiko T, Horino K, Baba Y, Mizumoto $\mathrm{T}$, et al. Intrahepatic dissemination of hepatocellular carcinoma after local ablation therapy. J Hepatobiliary Pancreat Surg. 2008;15(6):589-95. 
25. Santambrogio R, Opocher E, Costa M, Barabino M, Zuin M, Bertolini E, et al. Hepatic resection for "BCLC stage A" hepatocellular carcinoma. The prognostic role of alpha-fetoprotein. Ann Surg Oncol. 2012;19(2):426-34.

26. Kim HS, Park JW, Jang JS, Kim HJ, Shin WG, Kim $\mathrm{KH}$, et al. Prognostic values of alpha-fetoprotein and protein induced by vitamin $\mathrm{K}$ absence or antagonistII in hepatitis B virus-related hepatocellular carcinoma: a prospective study. J Clin Gastroenterol. 2009;43(5):482-8.

27. Chen Y-L, Chen C-H, Hu R-H, Ho M-C, Jeng Y-M. Elevated preoperative serum CA19-9 levels in patients with hepatocellular carcinoma is associated with poor prognosis after resection. ScientificWorldJournal. 2013;2013:380797.

28. Xia F, Wu L, Lau W-Y, Li G, Huan H, Qian C, et al. Positive lymph node metastasis has a marked impact on the long-term survival of patients with hepatocellular carcinoma with extrahepatic metastasis. PloS One. 2014;9(4):e95889.

29. Hasegawa K, Makuuchi M, Kokudo N, Izumi N, Ichida T, Kudo M, et al. Impact of histologically confirmed lymph node metastases on patient survival after surgical resection for hepatocellular carcinoma: report of a Japanese nationwide survey. Ann Surg. 2014;259(1):166-70.

30. Wu T, Ma X-A, Wang G-Q, Li Q, Li M-J, Guo J-Y, et al. $\mathrm{ABO}$ blood type correlates with survival in hepatocellular carcinoma following hepatectomy. Sci Rep. 2017;7(1):4412.

31. Gao F, Li X, Geng M, Ye X, Liu H, Liu Y, et al. Pretreatment neutrophil-lymphocyte ratio: an independent predictor of survival in patients with hepatocellular carcinoma. Medicine (Baltimore). 2015;94(11):e639.

32. 32. Akahoshi H, Taura N, Ichikawa $T$, Miyaaki $\mathrm{H}$, Akiyama M, Miuma S, et al. Differences in prognostic factors according to viral status in patients with hepatocellular carcinoma. Oncol Rep. 2010;23(5):1317-23.

33. Trevisani F, Magini G, Santi V, Morselli-Labate AM, Cantarini MC, Di Nolfo MA, et al. Impact of etiology of cirrhosis on the survival of patients diagnosed with hepatocellular carcinoma during surveillance. Am J Gastroenterol. 2007;102(5):1022-31.

34. Lai M, Hyatt BJ, Nasser I, Curry M, Afdhal NH. The clinical significance of persistently normal ALT in chronic hepatitis B infection. J Hepatol. 2007;47(6):760-7.

35. Li Bin, Yu Yao, He Yifeng, Fan Jia, Wu Zhiquan, Zhou Wei, et al. Value of the conventional liver function tests in the assessment of hepatic reserve. Chin J Hepatobiliary Surg. 2011;2011(10):805-8.

36. Strasak AM, Rapp K, Brant LJ, Hilbe W, Gregory $\mathrm{M}$, Oberaigner $\mathrm{W}$, et al. Association of gammaglutamyltransferase and risk of cancer incidence in men: a prospective study. Cancer Res. 2008;68(10):3970-7.
37. Hann H-W, Wan S, Myers RE, Hann RS, Xing J, Chen B, et al. Comprehensive Analysis of Common Serum Liver Enzymes as Prospective Predictors of Hepatocellular Carcinoma in HBV Patients. PLoS ONE. 2012;7(10):e47687.

38. Nojiri S, Joh T. Albumin suppresses human hepatocellular carcinoma proliferation and the cell cycle. Int J Mol Sci. 2014;15(3):5163-74.

39. Nojiri S, Kusakabe A, Shinkai N, Matsuura K, Iio E, Miyaki T, et al. Factors influencing distant recurrence of hepatocellular carcinoma following combined radiofrequency ablation and transarterial chemoembolization therapy in patients with hepatitis C. Cancer Manag Res. 2011;3:267-72.

40. Wan G, Gao F, Chen J, Li Y, Geng M, Sun L, et al. Nomogram prediction of individual prognosis of patients with hepatocellular carcinoma. BMC Cancer. 2017;17(1):91.

41. Ji F, Liang Y, Fu S-J, Guo Z-Y, Shu M, Shen S-L, et al. A novel and accurate predictor of survival for patients with hepatocellular carcinoma after surgical resection: the neutrophil to lymphocyte ratio (NLR) combined with the aspartate aminotransferase/ platelet count ratio index (APRI). BMC Cancer. 2016;16:137.

42. Gomez D, Farid S, Malik HZ, Young AL, Toogood GJ, Lodge JPA, et al. Preoperative neutrophil-tolymphocyte ratio as a prognostic predictor after curative resection for hepatocellular carcinoma. World J Surg. 2008;32(8):1757-62.

43. Zheng Y-B, Zhao W, Liu B, Lu L-G, He X, Huang $\mathrm{J}-\mathrm{W}$, et al. The blood neutrophil-to-lymphocyte ratio predicts survival in patients with advanced hepatocellular carcinoma receiving sorafenib. Asian Pac J Cancer Prev. 2013;14(9):5527-31.

44. Lee SS, Shin HS, Kim HJ, Lee SJ, Lee HS, Hyun $\mathrm{KH}$, et al. Analysis of prognostic factors and 5 -year survival rate in patients with hepatocellular carcinoma: a single-center experience. Korean J Hepatol. 2012;18(1):48-55.

45. Long TCD, Bac NH, Thuan ND, Dat LT, Viet DQ, Chuong LCHQ. Laparoscopic liver resection: 5-year experience at a single center. Surg Endosc. 2014;28(3):796-802.

46. Jiang CL, Tang D, Wang Y, Liang LJ, Ren QQ, Kuang M. Application of a three-dimensional operation planning system for precise hepatectomy in patients with giant hepatocellular carcinoma. Chin J Dig Surg. 2012;11(2):111-5.

47. Wang JD, Shen J, Zhou XP, Zhuang YP, Zhou Di, Yang Y, et al. Comprehensive measures for improving the radical resection rate and safety of Bismuth-Corlette type III hilar cholangiocarcinoma. Chin J Surg. 2013;51(7):596-9. 